\title{
A prova como um instrumento de avaliação para a aprendizagem
}

\author{
Evaristo José das \\ Mangas \\ Universidade da Beira Interior, \\ Departamento de Matemática, \\ Covilhã, Portugal / Instituto Superior \\ de Ciências da Educação da Huíla, \\ Huíla, Angola
}

\dasmangas2@gmail.com

\section{A prova Como um Instrumento de Avaliação para a Aprendizagem}

\begin{abstract}
The main objective of this paper is to present some reflections regarding to mathematic test as a tool of assessment for learning, that is to say, to expose what a test is, from a pedagogical point of view; how to elaborate it; how many questions should a test have; what is its social and pedagogical purpose. Additionally, some differentiated suggestions of assessment are presented in order that the test has a social inclusion character, highlighting the learning of all rather than only few. Suggestions are also made to mathematic teachers in order to pedagogically use both mistakes and successes of students' productions in the process of composing answers for each of the given questions presented in the test. It was decided to start with what we understand as a test in the pedagogical scope and, forward, reflections followed on how to elaborate a test, the test matrix and the answer key proposal. Through this paper we expect to contribute to improvement of mathematics teaching and learning process, leading mathematics teachers and students improving the design of the test as an assessment tool for leaning and deconstructing the conception of the test as being the boogieman that punishes students.
\end{abstract}

Key words: Test; Matrix; Correction; Inclusion; Assessment.

\section{Resumo}

O principal objetivo deste texto, consiste em apresentar algumas reflexões sobre a prova de matemática como um instrumento de avaliação para a aprendizagem, isto é, mostrar o que é uma prova do ponto de vista pedagógico, como elaborá-la, quantas perguntas devem comportar uma prova, qual a sua função social e pedagógica. Ainda são apresentadas algumas sugestões diferenciadas de avaliação para que a prova tenha um caráter de inclusão social evidenciando a aprendizagem de todos e não apenas de alguns. Também são apresentadas sugestões aos professores de matemática no sentido de fazer um aproveitamento pedagógico quer dos erros como dos acertos nas produções dos alunos no processo de composição de respostas para cada uma das questões presentes na prova. Decidiu-se por começar no que entendemos como prova em âmbito pedagógico e seguiram-se reflexões sobre como elaborar uma prova, matriz de prova e proposta de correção modelo. Através deste texto esperamos contribuir para melhoria do processo de ensino aprendizagem da matemática, orientando os professores de matemática e alunos na melhoria da conceção da prova como um instrumento de avaliação para a aprendizagem e desconstruir a conceção que se tem da prova como sendo o bicho papão que pune os alunos.

Palavras-chave: Prova; Matriz; Correção; Inclusão; Avaliação. 


\section{INTRODUÇÃO}

Não obstante a realização de provas ser uma prática diária nas nossas escolas, há pouca reflexão documentada relativamente, sobre o que é? Como elaborar? Para que serve? Que conclusões se pode tirar dos resultados da mesma? E até que ponto os resultados da mesma, reflete o trabalho do professor?

Das buscas bibliográficas feitas em projectos como TurmaMais, em livros de autores que refletem sobre a avaliação, como, por exemplo, [1], [2], [3] e em revistas sobre avaliação educacional, como, [4], ficamos com a sensação de que há falta de textos voltados à reflexão das perguntas anteriormente formuladas, com exceção desta última [4] que apresenta pontos precisos sobre a prova como instrumento de avaliação. O nosso texto vem precisamente, para preencher este vácuo, fornecendo assim, alguns subsídios no sentido de auxiliar os professores e não só, na melhoria das suas práticas pedagógicas, com particular realce na elaboração de provas de matemática.

Temida pelos alunos e questionada quanto aos resultados, a prova deixou de ser o único instrumento de avaliação usado pelo professor. Hoje, este dispõe de outras ferramentas para verificar o conhecimento da turma. Contudo, isso não significa que a prova deva ser banida das salas de aulas. Quando elaborada com precisão, pode ser uma ótima aliada para produzir um bom diagnóstico do que a turma aprendeu. $O$ resultado de uma prova vai servir de parâmetro para que o professor aprimore seu planejamento (Sic.) e seu trabalho em sala de aula [5].

Existem diferentes instrumentos de avaliação da e para a aprendizagem dos quais podemos destacar, os testes (provas), os questionários, as escalas, os portfólios, as rubricas e as fichas de verificação. Mas, "apesar da necessidade de tornar a avaliação contínua e diversificada, a simples observação do professor nunca é suficientemente profunda e individualizada em uma classe com dezenas de estudantes. A avaliação por escrito, portanto, sempre terá sua importância" [6].

Assim neste texto, começamos por conceituar a prova como instrumento de avaliação para a Aprendizagem, como elaborar uma prova, matriz de prova e proposta de correção modelo. Este texto representa uma síntese do que até agora reunimos em termos de bibliografia sobre a prova.

\section{A PROVA COMO UM INSTRUMENTO DE AVALIAÇÃO PARA A APREN- DIZAGEM}

Em âmbito pedagógico, a prova é um instrumento de avaliação, destinado a medir o nível de conhecimentos e de competências científicas, por escrito, e classificar cada um dos avaliados em função dos resultados obtidos. Tradicionalmente, falar de prova é falar de avaliação pedagógica, visto que, as provas são realizadas nas escolas e são 
da inteira responsabilidade dos professores em grande medida.

Mais do que um teste, a prova precisa ser encarada como um grande instrumento de avaliação, cujo propósito principal é o de ajudar o aluno a aprender, ajudar o professor na identificação dos conceitos que foram corretamente assimilados e, através desta, apresentar sugestões de estudos e/ou estratégias metodológicas para os conceitos não corretamente assimilados.

A prova como elemento de certificação de aprendizagens e das competências desenvolvidas, contribui no processo de tomada de decisões para a classificação dos alunos, permitindo enquadrá-los em grupos cuja característica é o domínio de determinado conteúdo.

As questões presentes numa prova de matemática, antes de mais, precisam refletir todos os conteúdos estudados, e não apenas um único conteúdo, para que o resultado a ser obtido por cada aluno avaliado possa "as vezes" traduzir suas capacidades, competências, hábitos e habilidades, pois que segundo [3, p. 84], "para que a Avaliação, possa ser tão rigorosa quanto possível, para que possa ter a credibilidade que se exige e para que os seus resultados possam ter real significado para todos os envolvidos, é necessário compreender e assumir a sua natureza e os seus aspectos mais controversos".

Perante a diversidade de dificuldades que se enfrentam no processo de conceção da prova, como um instrumento de avaliação para a aprendizagem, é necessário a nosso ver, que se faça uma prova que comporte todos os assuntos estudados, para que através da classificação (informação) obtida, permita ao professor e ao aluno a tomada de melhores decisões quanto ao curso que deve ser dado à aprendizagem e ao ensino [3, p. 98]. Esta forma de avaliação permite também avaliar os conteúdos mais complexos, ver e verificar o enorme aparato de conhecimentos no sentido de identificar as aprendizagens desenvolvidas ao longo de um Semestre, um determinado período ou ano letivo.

Um caminho para o desenvolvimento da prova de matemática são os princípios e normas estabelecidos pela NCTM (National Council of Teachers of Mathematics) de modo a que aos olhos dos alunos a matemática não pareça um conjunto de temas soltos ou que seja reduzida a perceção de que a matemática não passa das aborrecidas fórmulas com que se deparam os alunos.

Os princípios da matemática escolar são segundo [7, p. 11] o princípio da equidade, currículo, ensino, aprendizagem, avaliação e o princípio da tecnologia. As normas constituem as descrições daquilo que o ensino da matemática deverá habilitar os alunos a saber fazer e elas dividem-se em dois grupos que são: normas de conteúdonúmeros e operações, álgebra, geometria, medida e análise de dados e normas de 
processos matemáticos-resolução de problemas, raciocínio e demonstração, comunicação, conexões e representação [7, p. 31].

A prova de matemática não deve apenas ser vista como uma prática de mera atribuição de classificação ao aluno, vale recordar que, ela é, antes demais, o resultado de um processo qualitativo e formativo, como por exemplo, a assiduidade do aluno, o número de problemas bem resolvidos pelo aluno, a frequência da participação nas atividades das aulas e a atitude do aluno perante a aprendizagem.

Pensamos que a prova é tanto um instrumento de avaliação formativa, quanto um instrumento de avaliação sumativa.

A avaliação formativa e a avaliação sumativa são conceptualmente diferentes, mas todas elas convergem para um mesmo fim. É de aceitação geral que, a avaliação formativa acompanha todo o processo de ensino aprendizagem, ao passo que, a avaliação sumativa deve ser feita em momentos próprios. Segundo [3, p. 91], "(...) as avaliações formativas têm problemas vários de validade e de habilidade, por ocorrerem em contextos muito específicos, faltando-lhes, por isso, consistência para que possam servir propósitos sumativos".

A avaliação formativa e a avaliação sumativa não se podem confundir uma com a outra. Têm propósitos distintos, ocorrem em momentos distintos e têm uma inserção pedagógica distinta [3, p. 94].

No que respeita à prova, a mesma pode ser vista como um elemento de avaliação formativa, enquanto instrumento de avaliação para a Aprendizagem, mediando a aprendizagem do aluno e, como elemento de avaliação sumativa, enquanto instrumento de avaliação da Aprendizagem, tendo como fim último, classificar os alunos.

\section{COMO ELABORAR UMA PROVA?}

Para elaborar uma prova de matemática, o professor precisa, entre outros requisitos, conhecer profundamente o conteúdo (normas de conteúdo e/ou processos matemáticos) a avaliar, e saber dos objetivos gerais e específicos presentes no programa da cadeira referente à(s) unidade(s) a avaliar e os princípios da matemática escolar.

O professor de matemática deve conhecer os princípios norteadores da matemática escolar com particular atenção o princípio da avaliação e em combinação com os outros princípios como, o princípio da equidade, currículo, ensino, aprendizagem e tecnologia elaborar uma prova que permita que todos os alunos aprendam matemática de forma estimulante e desafiadora.

Elaborar uma prova de matemática não é uma tarefa fácil em que professores sem comprometimento com o ato educativo, são bem-sucedidos. A prova elaborada por um especialista, ou por uma pessoa devota ao estudo, possui sempre um carácter 
holístico. Nela são percorridos objetivos pedagógicos, emanados pelas instâncias a quem compete decidir sobre os mais variados intentos com o ato educativo. Nunca 0 objetivo de uma prova deve ser "fazer mal ao aluno", como acontece muitas vezes nas nossas escolas de hoje em que os professores valem-se das provas para disciplinar, impor ordem ou ainda com o objetivo de penalizar o aluno. Muitos professores fazem da avaliação, concretamente da prova de matemática, uma espécie de monstro incontrolável que lança o desespero, a incompreensão e a desconfiança, junto de quem é avaliado, quando deveriam fazer dela, um processo (ou instrumento) responsável pela transformação, reflexão e mobilização do aluno, para uma aprendizagem mais efetiva, como bem lembra [3]:

\footnotetext{
para que a avaliação possa ser um processo ao serviço da melhoria e do bemestar de quem é avaliado, é necessário que os seus propósitos sejam bem compreendidos por todos os intervenientes, e que o processo seja tão transparente e tão consensual quanto possível. Por outro lado, é imprescindível que quer os avaliados quer os avaliadores estejam (ou sejam) devidamente preparados para desenvolver o processo de avaliação nesse sentido $[3, p$. 84].
}

Tendo em conta as aprendizagens essenciais (objetivos) para cada nível de ensino, as provas (testes) devem ser elaboradas conforme as várias variáveis de interesse em avaliação educacional, como o conhecimento, habilidades ou atitudes do aluno que podem se traduzir na sua produção escrita, produção oral, nível de raciocínio e argumentação na formulação de repostas quanto aos assuntos estudados ou onde se pretende chegar.

A prova tem que ser composta de diferentes tipos de perguntas (abertas ou fechadas), para que tenha um carácter de inclusão social, sendo este, um dos objetivos da educação. O propósito principal da avaliação é ajudar os alunos e os professores a aprender e a ensinar melhor [3], [7, p. 23].

O processo de avaliação pedagógica na sala de aulas deve carregar consigo o carácter inclusivo da educação coletiva, educação no todo e para todos, por isso o professor, ao planificar determinados exercícios, deve sempre mobilizar e pensar em todos para a aprendizagem. É tarefa do professor "(. . ) garantir que todos os alunos tenham uma oportunidade de demonstrar clara e completamente aquilo que sabem e são capazes de fazer" [7, p. 25].

O professor precisa ser claro e objetivo ao formular cada uma das questões, para que não possa confundir a compreensão do aluno, como afirma [4, p. 245] "(...) é a partir de boas perguntas que os alunos terão condições de dar boas respostas". A prova, numa primeira instância, é um instrumento de avaliação para a aprendizagem do aluno e, em segunda instância, é igualmente um instrumento de avaliação de quem 
a elaborou, ou seja, é um instrumento de avaliação e co-avaliação em simultâneo. Através de uma prova, não só o aluno expressa o seu grau de conhecimento ou à sua ignorância quanto aos conteúdos avaliados, como também o professor expõe a sua perícia, o seu grau de profissionalismo ou incapacidade e o seu desconhecimento acentuado sobre um conteúdo, a sua falta de compromisso com o processo pedagógico e, consequentemente, o ato pedagógico outras características a que lhe são intrínsecas.

Como pedir ajuda nunca é demais, o professor além da sua experiência, importa ainda, partilhar com os colegas com horizontes para lá das fronteiras do seu conhecimento, para que na unidade e coesão mútua da classe docente se possam combinar as potencialidades de uns com as debilidades de outros.

Ao elaborar uma prova com um número reduzido de questões, muitas vezes os professores caem no absurdo de concluir que os bem-sucedidos na mesma, sabem muito e, os não bem-sucedidos não sabem nada. As perguntas da prova "(. . .) necessitam ser elaboradas com perguntas realmente relevantes que provoquem operações mentais que sejam diversificadas e adequadas à forma de ensino e ao nível da turma, com questões nem tão fáceis, que não causem desafio, nem tão complexas, que possam causar ansiedade e que sejam contextualizadas" [4, p. 250]. Vale recordar que o resultado de uma prova, não depende somente dos conhecimentos que cada um tem, mas também, em grande parte, do estado psicológico que cada um goza no momento de realização da prova.

Através dos resultados obtidos pelos avaliados durante sucessivas avaliações (provas), podemos identificar os perfis de saída de cada aluno e saber se são ou não capazes de transformar positivamente a sociedade à sua volta em face dos conhecimentos apreendidos, por isso, ao elaborar uma prova de matemática, um professor, precisa mobilizar os seus múltiplos conhecimentos e, o aluno, para responder cada uma das questões presentes, precisa também de mobilizar os seus vários conhecimentos do seu repertório cognitivo.

Ao final de cada unidade estudada, além das avaliações feitas ao longo dos estudos consecutivos, o professor deve elaborar uma prova que comporte questões capazes de integrar a unidade estudada e também, deve ser capaz também de se reinventar no desabrochar da sua imaginação criativa, para que possa elaborar uma prova com várias questões, de modos que quem não responder a uma questão, responda a outras e assim sucessivamente, porque segundo o Paradoxo da Invenção, "(. . .) é possível que seja mais fácil responder a muitas perguntas do que a uma só. O problema mais abrangente pode ser fácil de demonstrar; o problema mais genérico, mais fácil de resolver" [8, p. 108]. 
É inconcebível que os alunos tenham estudado várias unidades (conteúdos) e a prova tenha apenas uma ou duas questões, primeiro, porque através de uma ou duas questões não é possível identificar um perfil de saída mais racional, segundo, porque através de uma prova com uma ou duas questões imergimos para práticas de exclusão social, dando a possibilidade de favorecer o aluno que domina apenas a unidade avaliada e, desfavorecer o aluno que, às vezes, reúne conhecimentos reduzidos da unidade avaliada, mas que reúne conhecimentos profundos sobre quase todas as outras unidades e, finalmente, porque devemos ser apologistas do Paradoxo da Invenção que, a nosso ver, cumpre com o carácter de inclusão social da educação.

O professor deve fazer as perguntas certas a cada aluno. Ao conhecermos bem os nossos alunos e até que ponto eles compreendem cada objetivo de aprendizagem, ajustamos nossas perguntas à compreensão de cada um. Cada aluno tem diferente nível de compreensão e nosso principal objetivo é o crescimento [9, p. 83].

Através do resultado da prova, o Professor precisa fazer uma autoavaliação, e verificar se não falhou em seu dever, já que, "um dos mais importantes deveres do professor é o de auxiliar os seus alunos, o que não é fácil, pois exige tempo, prática, dedicação e princípios firmes" [8, p.1].

As provas em série são um instrumento de arbitrariedade e de exclusão social quando não cumprem com o carácter da educação diferenciada, aquela que respeita e valoriza os saberes do território em que se se circunscreve a escola, ou seja, aquela que evidencia a etnomatemática do aluno. Aplicar uma prova em série só porque a turma é numerosa nada tem de pedagógico. As provas em série devem favorecer a avaliação da aprendizagem para o domínio. Dado que, a aprendizagem para o domínio consiste em que os alunos alcancem uma série de objetivos no próprio ritmo. Em vez de todos os alunos se engajarem nos mesmos temas, cada um se concentra na busca de determinados objetivos [9, p. 47], os alunos devem ser avaliados também de acordo com as suas necessidades de aprendizagem e características individuais para uma personalização e individualização da aprendizagem.

As provas em série terão um objetivo pedagógico sempre que, na aprendizagem para o domínio cada aluno é avaliado de maneira diferente, conforme as suas características e necessidades; no entanto, adotam-se como critérios os mesmos objetivos. Além disso, os estudantes recebem versões diferentes do exame, sempre que são avaliados [9, p. 49].

O carácter de inclusão social do ato educativo deve ser capaz de proporcionar uma educação diferenciada diante da coletividade também na realização de uma prova de matemática em particular, ou de uma avaliação, em geral. 


\section{MATRIZ DE PROVA}

A matriz de prova é um documento onde estão delimitados os conteúdos, as expectativas de aprendizagens de cada uma das questões, a caracterização da prova, o material a utilizar, os critérios de correção, a cotação e a duração da prova.

Não obstante aos critérios de correção que se possam estabelecer para a correção de uma prova enquanto instrumento de avaliação, a "avaliação não é uma ciência exata pelo que a subjetividade é uma característica inerente à este processo e estará sempre presente" [2, p. 112].

Sobre o tempo de realização da prova é importante que o professor seja capaz de "formular questões de acordo com o tempo disponível para a realização, entendendo que este não deve ser um elemento de pressão, pois pode comprometer o trabalho do aluno" [4, p. 246].

Na matriz de prova devem estar presentes a função social e pedagógica da prova. De realçar que a função social da prova corresponde ao procedimento administrativo da escola, onde a partir dos resultados obtidos pelos alunos garante-se a promoção dos mesmos com a aprovação ou reprovação. Na matriz estão referenciadas o posicionamento da prova no calendário letivo e a respetiva classificação da prova se é bimestral, trimestral ou de exame e a sua influência no resultado final do aluno.

Relativamente a função pedagógica da prova, a matriz se presta a informar os conteúdos a avaliar, os objetivos a serem percorridos em cada questão, os meios a utilizar na referida prova para que se garanta a construção da aprendizagem e a análise do processo de ensino aprendizagem.

Na elaboração da matriz da prova o professor tem a possibilidade da colaboração dos outros professores da coordenação de matemática, em particular, do coordenador da disciplina e de uma forma geral, da secretaria da educação para junto elencar os mais variados objetivos com a referida prova.

A matriz da prova é um documento que deve ser do conhecimento do aluno e da comunidade escolar, por isso deve ser publicada antes da realização da prova.

\section{CORREÇÃo MODELO OU PROPOSTA DE CORREÇÃo (CHAVE DA PROVA)}

Toda prova deve ter sua respetiva proposta de correção modelo ou chave, ou seja, cada uma das questões presentes no enunciado deve ter sua correção e a respetiva cotação por cada fase da construção da resposta da mesma. A correção da prova, permite ao professor, saber e identificar as questões mais simples ou complexas da prova, cuja resolução das mesmas é necessário uma mobilização de vários conhecimentos e fazer uma autoavaliação do seu conhecimento, isto é, "(. . .) o professor deve procurar 
colocar-se no lugar do aluno, perceber o ponto de vista deste, procurar compreender o que se passa em sua cabeça e fazer uma pergunta ou indicar um passo que poderia ter ocorrido ao próprio estudante" [8, p. 1].

Ao elaborar uma prova sem a respetiva correção, pode ocorrer casos em que, as questões que o aluno manifestou desconhecimento em responder, não constituam apenas dificuldades suas, como também do professor que as elaborou. Na hora da correção conjunta, na sala de aulas, é quase certo de que será uma grande vergonha para o professor.

Como visto em [4], muitos professores manifestam uma postura de resistência face aos novos paradigmas de educação, como, o construtivismo e a aprendizagem significativa, assim como por metodologias ativas da sala de aula invertida. Os professores precisam saber que "todo indivíduo vivo desenvolve conhecimentos e tem um comportamento que reflete esse conhecimento, que por sua vez vai-se modificando em função dos resultados do comportamento. Para cada indivíduo, o seu comportamento e o seu conhecimento estão em permanente transformação, e relacionam-se numa relação que poderíamos dizer de verdadeira simbiose, em total interdependência, [10, p. 18]".

No processo de correção de uma prova, muitos professores, acabam sendo "tradicionalistas", requerendo do aluno, reprodução textual dos conteúdos, facto que diverge com muitos dos objetivos do processo de ensino aprendizagem, que é o de formar seres pensantes, capazes de resolver os mais variados problemas sociais. Além do mais, as vezes cometem-se erros por causa do sentimento de superioridade ao olharse como detentor de todo o conhecimento, mas também é bem verdade que:

(...) o matemático, que dispõe de vastos conhecimentos, está mais exposto do que o principiante ao risco de mobilizar excesso de conhecimentos e de preparar um argumento desnecessariamente complexo. Em compensação, o matemático experiente encontra-se em melhor posição do que o principiante para apreciar a reinterpretação de uma pequena parte do resultado e, finalmente, chegar, acumulando essas pequenas vantagens, a refundir todo o resultado. [8, p. 61]

Os professores dizem perseguir uma "Escola de qualidade", sendo exigentes na avaliação; no entanto, contribuem sobremaneira para o afastamento de milhares de crianças e jovens das Escolas do Ensino Geral e da Universidade através do fator de reprovação continuada (sic.), [6, pp. 58-59].

Os professores precisam assumir uma postura consciente no processo de elaboração e correção da prova de matemática, para não revelarem contradição na sua existência como professores de hoje, ao manifestarem práticas avaliativas da "geração 
passada", centrando-se no carácter reprodutor. Por essas "falhas", pensamos recair responsabilidades não somente a geração passada, mas também aos professores que permanecem estáticos no tempo dinâmico. A primeira forma que um Professor tem de ensinar, aprender e avaliar, é a forma pela qual foi ensinado, forma como aprendeu e como o avaliaram, afinal de contas, "a prática avaliativa do professor reproduz e (assim) revela suas vivências como estudante e como educador" [6, p. 13].

A correção modelo é apenas um guia de solução para as várias questões presentes numa prova, não deve ser encarada como uma coisa rígida de tal forma que todos os alunos tenham que responder às questões da prova tal igual à correção. Diferentes pessoas olham sobre as mesmas coisas de forma diferentes e às vezes são capazes de atribuírem diferentes significados conforme o seu repertório cognitivo. Tem que se respeitar a mente criativa do aluno, diferentes caminhos da racionalidade podem levar ao mesmo resultado, daí a nome de proposta de correção à chave da prova.

As exigências avaliativas, desprovidas, muitas vezes, de significado quanto ao desenvolvimento efetivo das crianças e dos jovens, favorecem a manutenção de uma Escola elitista e autoritária [6, p. 59].

A prova, como instrumento de avaliação para a aprendizagem, não consiste apenas em conferir classificação, grau, ou nota sem interpretação desses resultados, mas também serve para questionamentos quanto ao seu significado e poder, dado que "a pura e simples atribuição de notas não é suficiente para informar quanto ao nível de aprendizagem atingido pelo aluno" [4, p. 243].

Através de uma prova não é possível avaliar todas aprendizagens possíveis, é necessário, modos e instrumentos diferenciados de avaliação adequados ao trabalho realizado na sala de aulas e a natureza de diversas aprendizagens [2, p. 112].

Do carácter inclusivo da educação resulta que cada aluno deva ser avaliado conforme as suas necessidades de aprendizagem garantindo assim uma personalização do ato de ensinar e de aprender de modo a se efetivar a avaliação e aprendizagem para o domínio.

A perspetiva de uma avaliação para as aprendizagens assenta na assunção de que os estudantes fazem parte do processo, de forma a poderem tomar decisões sobre o caminho a percorrer em direção às metas pretendidas [2, p. 114].

O objetivo da prova de matemática tem que ser promover a aprendizagem do aluno e por esta razão, no processo de correção de provas, o professor deve procurar fazer um aproveitamento pedagógico das produções dos alunos, orientando-os assim para a aprendizagem, porque os erros e os acertos dos alunos não evidenciam somente o que o aluno sabe ou não sabe, "qualquer produção, seja aquela que apenas repete uma resolução-modelo, seja a que indica a criatividade do estudante, tem características 
que permitem detetar as maneiras como o aluno pensa e, mesmo, que influências ele traz de sua aprendizagem anterior, formal ou informal. Assim, analisar as produções é uma atividade que traz, para o professor e para os alunos, a possibilidade de entender, mais de perto, como se dá a apropriação do saber pelos estudantes". [11, p. 15].

As escolas, os alunos e a sociedade têm medo das provas de matemática por causa das taxas de retenção em determinados ciclos de ensino. É muita pressão psicológica da parte de todos envolventes do processo de ensino e aprendizagem. Quando bem elaboradas podem constituir-se num instrumento de recolha de indicador que afira a qualidade da aprendizagem dos alunos e do ensino por parte dos professores.

Se os professores estiverem razoavelmente seguros sobre o que seus alunos sabem atualmente, então os professores podem adaptar com mais precisão quaisquer atividades instrucionais futuras para promover o que seus alunos precisam aprender [12, p. 10].

\section{EFEITO HALO NA CORREÇÃO DA PROVA}

O objetivo de aferir o cumprimento dos objetivos de ensino podem vir minados pela perceção que o professor tem do aluno aquando das vivências anteriores em sala de aula. Às vezes, pode o professor ao saber o nome do autor da prova atribuir uma classificação que venha a beneficiar ou a prejudicar o aluno sem a leitura da produção textual do aluno em cada item de resposta, ou seja, a caraterística apresentada pelo aluno em um único dia pode se constituir em estereótipo global do aluno.

Para alguns professores, um aluno nunca passa da nota " $x$ " (em desfavorecimento do aluno), porque quando o conheceu o aluno terá manifestado um grande desconhecimento sobre um determinado assunto e o professor o conotou como um aluno que não serve. Também existem aqueles casos em que a nota do aluno vem minada pela perceção que o professor teve do mesmo num dos dias em que manifestou grande compreensão sobre um assunto determinado e, por isso, o professor acha que o aluno sempre merece nota "y" em favorecimento do mesmo, por isso é necessário que o professor faça o esforço de "tentar se deter nas respostas e não no nome do aluno", como afirma [4, p. 252].

Em todos os casos, é preciso que o professor corrija minuciosamente cada fase de construção de resposta a cada item da prova. Lembrando que em aprendizagem para o domínio, cada aluno pode aprender qualquer conteúdo desde que tenha o tempo suficiente e o apoio necessário para a aprendizagem. O aluno pode se superar com a realização de provas que visam a mediação da aprendizagem.

Os níveis de desempenho dos alunos devem ser aferidos mediante provas com verdadeiro sentido pedagógico que garantam uma aplicação e contextualização dos 
conhecimentos de modo a que os alunos sejam capazes de atribuir significados ao que os rodeia e fazer do conhecimento uma necessidade constante de modo a garantir a sua inserção na sociedade. Das provas de matemática enquanto instrumento de avaliação para a aprendizagem se podem fazer grandes aproveitamentos pedagógicos através dos quais é possível obter informações de elevada qualidade, sobre o curso que se deve dar ao sistema educativo quanto a sua qualidade.

Não obstante as provas serem um grande instrumento de avaliação para a aprendizagem, "muitos dos conhecimentos dos alunos previstos oficialmente podem ser de difícil avaliação só utilizando testes de papel e lápis [1, p. 58]", por isso, o professor deve valer-se de outros instrumentos para a avaliação para a aprendizagem, como, por exemplo, os questionários, as escalas, os portfólios, as rubricas e as fichas de verificação.

\section{CONCLUSÃO}

A conceção da prova de matemática como um instrumento de avaliação para e da aprendizagem, visa ajudar os professores e alunos a ensinar e a aprender melhor, através de uma prova cujo objetivo é verificar o grau de conhecimento dos alunos nos assuntos abordados e a capacidade do Professor ao ensinar e ao requerer dos alunos um conhecimento profundo.

Os professores precisam fazer da realização da prova de matemática um momento em que o aluno tenha o prazer de confrontar seus múltiplos conhecimentos, através de perguntas corretamente elaboradas e cuja resolução das mesmas incentivem todos os alunos a aprender, tanto os mais dedicados, quanto os menos despertos. O carácter de inclusão social da educação nunca pode ser deixado para trás, por isso ao elaborar uma prova de matemática, o professor deve ter como alvo todos os alunos da turma, elaborando assim uma prova com diferentes tipos de perguntas (abertas ou fechadas) e com diferentes graus de complexidade, não esquecendo a faixa etária dos alunos.

A prova enquanto instrumento de avaliação para a aprendizagem deixa de ser um vetor de ansiedade, estresse, falta de confiança e baixa autoestima para o aluno quando os alunos e professores fazem das aulas, um ambiente de apropriação de conhecimentos em que a sua aferição seja um desejo de modo a regular a aprendizagem. Uma prova de matemática centrada na construção da aprendizagem é com certeza um grande instrumento que deve acompanhar o processo de ensino aprendizagem de modo a propiciar a mediação/regulação da aprendizagem.

\section{REFERÊNCIAS}

[1] ALFREDO, F. C. H. Políticas Educativas e Avaliação das Aprendizagens em Angola: Discursos e Práticas de Professores (2018). Tese de Doutorado (Educação) - Departamento de Ciências 
Sociais da Educação, Universidade do Minho. Portugal. [Google Scholar]

[2] CID, M.; FIALHO, I. Critérios de Avaliação: Da Fundamentação à Operacionalização. In: FIALHO, I.; SALGUEIRO, H. (org.). TurmaMais e Sucesso Escolar:Contributos teóricos e práticos. Évora: Centro de Investigação em Educação e Psicologia (2011), pp. 109-124. [Google Scholar]

[3] FERNANDES, D. Avaliar Para Melhorar as Aprendizagens: Análise e Discussão de Algumas Questões Essenciais. In: FIALHO, I.; SALGUEIRO, H. (org.). TurmaMais e Sucesso Escolar:Contributos teóricos e práticos. Évora: Centro de Investigação em Educação e Psicologia (2011), pp. 81-107. [Google Scholar]

[4] DE MORAES, D. A. F. Prova: instrumento avaliativo a serviço da regulação do ensino e da aprendizagem. Estudos em Avaliação Educacional, v. 22, n. 49 (2011), p. 233-258. [CrossRef] [Google Scholar]

[5] RODRIGUES, C. Como elaborar provas que ajudam na aprendizagem. Nova Escola, Gestão Escolar. [S.I.] Disponível em: https://gestaoescolar.org.br/conteudo/664/ como-elaborar-provas-que-ajudam-na-aprendizagem (2010) (acesso em 10 agosto 2020).

[6] HOFFMANN, J. M. L. Avaliaçäo: mito e desafio: uma perspectiva construtivista. Porto Alegre: Mediação, 2000

[7] NCTM. Princípios e Normas para a Matemática escolar. 2 ed. Lisboa: APM, 2008.

[8] POLYA, G. A arte de resolver problemas. Um novo aspecto do método matemático. Rio de Janeiro: interciência, 1995. [Google Scholar]

[9] BERGMANN, J.; SAMS, A. Sala de aula invertida: uma metodologia ativa de aprendizagem 1. ed. Rio de Janeiro, 2016. [Google Scholar]

[10] D'AMBROSIO, U. Etnomatemática-elo entre as tradições e a modernidade. Belo Horizonte: Autêntica, 2016.

[11] CURY, H. N. Análise de erros: o que podemos aprender com as respostas dos alunos. Belo Horizonte: Autêntica, 2013. [Google Scholar]

[12] POPHAM, W. J. Classroom assessment: What teachers need to know. 8 ed. Los Angeles: Pearson Education, 2017.

\section{BREVE BIOGRAFIA}

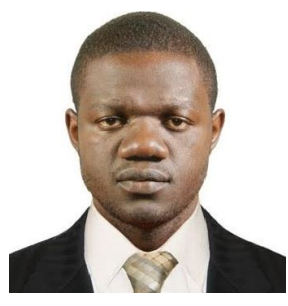

Evaristo José das MANGAS (D) https://orcid.org/0000-0001-6578-3198

Licenciado em Ensino da Matemática pelo Instituto Superior de Ciências da Educação da HuilaAngola, mestre em Matemática Para Professores pela Universidade da Beira Interior-Portugal e doutorando em Matemática e Aplicações na Faculdade de Ciências da UBI-Portugal, faz parte do centro de matemática da UBI. É professor de Matemática no Colégio № 852 "11 de Novembro"Lubango e professor colaborador assistente no ISCED-HUILA e desenvolve a sua investigação na área de Álgebra Linear e Multilinear, estudando o permanente de matrizes não negativas. 